\title{
Making Things Happen: Self- Leadership and Newcomers Socialisation
}

\author{
Robinson James \\ Department of Human Resource Management, University of Jaffna, Sri Lanka \\ robinson435@gmail.com
}

\begin{abstract}
Organisational socialisation scholars endlessly call for investigations on individuals' self-initiated activities during the transition into a new workplace. The current study aims to discover newcomers as active agents of their socialisation, through identifying the impact of newcomers' self-leadership on their socialisation into a new workplace. The present study was conducted with hundred and nineteen newcomers (male $=68$, female $=51$ ) who have less than one-year work experience in the current organisation working in the banking sector of Sri Lanka. Hierarchical multiple regression was utilised to analyse the data. Results indicated that the three-component of self-leadership: behaviour-focused strategies, natural rewards strategies, and cognitive thought strategies had a significant impact on newcomers socialisation, and these three components of self-leadership explain $35.9 \%$ of the variance in newcomers socialisation. Newcomers' profile variables (gender, marital status, age, and type of appointment) have no influence either on the three components of self-leadership or organisational socialisation. This study, by identifying the impact of the three parts of self- leadership on newcomers' socialisation in Sri Lankan context extends the organisational socialisation literature and help both organisation and newcomers to understand individuals' role in the socialisation process.
\end{abstract}

Keywords: Self-Leadership, Behaviour, Rewards, Cognition, Newcomers, Socialisation

\section{Introduction}

The transition into a new workstation is a problematic experience for newcomers (Cranmer, Goldman, \& Houghton, 2019; Saks \& Gruman, 2012). The transition is a more stressful experience, and this experience continues until they successfully socialise to the new organisational context. During the organizational socialisation, newcomers attain "the necessary knowledge and skills to perform their role and function effectively in their new social and organisational environment" (Ellis et al., 2017, p. 993). Also, organisational socialisation transmits organisational culture to newcomers and influences employee's attitudes and behaviours (Ashforth et al., 2007). Newcomers' successful socialisation leads to their well-being, work engagement and retention (James, 2020), and thus, enable organisations to get expected outcomes from the newcomers (Cranmer et al., 2019; James \& Azungah, 2019). Successful socialisation allows newcomers to understand the organisation and positively influences the expectation of both the organisation and the newcomers. Unsuccessful socialisation leads to newcomer's negative attitudes, 
low performance and high turnover, and hinder the expectations of both the organisation and newcomers (CooperThomas \& Anderson, 2006).

Organisational socialisation of newcomers has been studied for many decades (Kramer \& Miller, 2014). Traditionally it was assumed that the organisation is responsible for newcomers successful socialisation. However, organisations were unable to provide all the resources that newcomers needed to their successful socialisation (Saks \& Ashforth, 1997; James \& Azungah, 2020; Kowsikka \& James, 2019). Consequently, recent studies on organisational socialisation have focused on individuals' active role in the organisational socialisation process (Cranmer et al., 2019). Theories related to socialisation such as social cognitive theory (Bandura, 1986, 2001), uncertainty reduction theory (Berger \& Calabrese, 1975) and socialisation resource theory (Saks \& Gruman, 2012) suggests that individuals are self-organising and proactive organisms.

Newcomer's involvement in socialisation can be recognised through their self-initiated activities in the process of the organisational socialisation. Newcomer Self-initiated activities such as feedback-seeking, information-seeking, and engagement in positive framing help their successful socialisation process (Ashforth et al., 2007; Kowsikka \& James, 2019) and facilitate them to experience well-being and engage in their work (James, 2020). Individuals' self- initiated activities are more valuable than organisation's formal effort to socialise newcomers (Ashford
\& Black, 1996; Cranmer et al., 2019), and thus, researchers repeatedly focus on individuals self-initiated activities that facilitate successful socialisation. Recently, a few studies on newcomers' organisational socialisation investigate the impact of newcomers' proactive behaviour on the adjustment and socialisation process (Kowsikka \& James, 2019).

Self-leadership involves persons' general ability or skill that regulate their behaviour (Stewart et al., 2011). It is a process that facilitates a person to act and operate effectively through self-direct and self-motive (Neck \& Houghton, 2006). Self-leadership can provide a potential framework for recognising newcomer's self-initiated efforts that help their organisational socialisation. However, organisational socialisation literature has paid a lack of attention on newcomers' selfinitiated role in the socialisation process, mainly the role of the direct influence of self- initiated leadership on newcomers' organisational socialisation. Notably, there is no research on this area in the Sri Lankan context. Therefore, this study aims to discover newcomers as active partners of their socialisation, through identifying the impact of newcomers' self-leadership on their socialisation into a new workplace. This study, by identifying the influence of the three components of self- leadership on newcomers' socialisation extends the socialisation literature and help both the organisation and newcomers to understand individuals' role in the socialisation process. 


\section{Literature Review and Hypotheses Development}

\section{Self-leadership}

The self-leadership idea emerged from the concept of control theory (Carver \& Scheier, 1982). According to Manz (1992), self-leadership is a process that enables a person to behave and perform towards desirable outcomes through self-direct and self-motive. It is an individual's general ability or skill to involve in the regulation of his/her behaviour (Stewart et al., 2011). According to Manz (1986), individuals are self-leaders, and they apply particular behavioural and cognitive techniques to achieve their desired consequences. Manz (1986) defines self-leadership as "a comprehensive self-influence perspective that concerns leading oneself toward the performance of naturally motivating tasks as well as managing oneself to do work that must be done but is not naturally motivating" (p. 589). Selfleadership and autonomy are the different concepts; autonomy is related to an individual's ability to take his/ her decision. Still, self-leadership involves increasing personal effectiveness through raising self-consciousness and feeling of capability (Neck \& Manz, 2012). Self-leadership functions through three distinct strategies; behaviour-focused strategies, natural reward strategies and constructive thought strategies (Neck \& Manz, 2012, Politis, 2006).

Behaviour-focused strategies enable individuals to realise their purposes through self-awareness (Neck \& Manz, 2012). Behaviour-focused strategies comprise self-observation, self-goal setting, self-reward, self-punishment, and self-cueing. Self- observation is an antecedent of self-awareness. Selfobservation enable individuals to understand why and when they display particular behaviours and give information on how to manage their behaviour (Houghton \& Neck, 2002). The self-assessment allows for individuals to set their specific goals which provide direction and purpose. The particular goals help individuals to focus on their journey on achievement. Both self-rewards and self-punishment functions as effective reinforce. Selfrewards control individuals' behaviour by satisfying their needs. Similarly, self-punishment controls individuals' behaviour by withdrawing themselves from their preferred things (Neck \& Manz, 2012). Self-cueing help individuals to remind their job and catch their attention, and thus enable individuals for their effective behaviour.

Natural reward strategies were founded on intrinsic motivation theory. Natural reward strategies enable individuals to pay attention to the positive and joyful aspects of a given task (Houghton \& Neck, 2002; Neck \& Houghton, 2006). Natural reward strategies facilitate people to engage in intrinsic motivation by giving detailed instructions. It involves creating more enjoyable features into a given task (Neck \& Manz, 2012). Natural rewards strategies enhance individuals' feelings of competence, self-control and a sense of purpose. Constructive thought strategies involve in building productive habits. These strategies include recognising and replacing worthless faiths and guesses, practising mental imagery and optimistic self-talk (Neck \& Houghton, 2006). 
Constructive thought strategies enable individuals to improve their effectiveness by creating a pattern of positive thinking.

A considerable amount of studies have found the positive impact of selfleadership on employees work-related consequences such as individual performance (Frayne \& Geringer 2000; Prussia, Anderson, \& Manz, 1998) job satisfaction (Neck \& Manz 1996), positive affect (Houghton et al., 2012), innovative behaviour (Carmeli, Meitar, \& Weisberg, 2006). Further, Murphy and Ensher (2001) and Raabe et al. (2007) explored that self-leadership positively influence longstanding career achievements. Prussia et al., (1998), Latham and Frayne (1989) and Houghton et al., (2012) reported that self-leadership functions as a predictor of self-efficacy. Bailey et al. (2018) found that self-leadership is related to self-regulatory processes. Also, it was found that self-leadership reduces employees' absenteeism (Frayne and Latham 1987) and work-related anxiety (Saks \& Ashforth, 1996). However, the role of self-leadership on adjustment during individuals' role transition has not been sufficiently discussed in the organisational socialisation literature.

\section{Organisational Socialisation}

Organisational socialisation is a process where employees learn the values, behavioural norms, social competencies, and abilities and skills necessary to perform the required task and become an acceptable member the organisation (Louis, 1980). Similarly, Van Maanen and Schein (1979) describes organisational socialisation as a process by which newcomers become involved in learning required attitudes, behaviours, knowledge, and skills for their effective function and become an active team member of the organisation (Van Maanen \& Schein, 1979).

Before starting their career, employees form expectations about organisational members, relationship and task. Nevertheless, unexpectedly, there are differences between the expectations and the reality, and this disparity establishes uncertainty and anxiety. To reduce uncertainty and anxiety, employees engage in learning their work roles, building associations with co-workers and adopting organisational culture (Taormina, 2008). This adjustment process continues until they become welladjusted and an acceptable member of the organisation. At this moment, newcomers create certainty and reduce stress; that is, they are socialised successfully. Successful socialisation enables newcomers to understand the organisation and positively influences the expectation of both the organisation and the newcomers. Also, organisational socialisation transmits organisational culture to newcomers and influences employee's attitudes and behaviours (Ashforth et al., 2007; Saks \& Guruman, 2010). Unsuccessful socialisation leads to newcomer's negative attitudes, low performance and high turnover, and hinder the expectations of both the organisation and newcomers (Cooper-Thomas \& Anderson, 2006)

John (1986)' empirical investigation found that adjustment indicators such as role ambiguity, intention to quit, and role conflict were negatively associated 
with traditional socialisation tactics, while job satisfaction and organisational commitment were positively associated with these tactics. Following John (1986), considerable amounts of studies (e.g., Ashforth \& Saks, 1996; Ashforth et al., 2007; Bauer et al., 2007; Black \& Ashforth, 1995; Saks \& Ashforth., 1997) have examined the association between socialisation tactics and adjustment indicators, and have confirmed that socialisation tactics influence adjustment and socialisation outcomes. Two meta-analyses (Bauer et al., 2007; Saks et al., 2007) explored the view that socialisation tactics lead to traditional socialisation outcomes (job satisfaction) through proximal outcomes (e.g. perceived fit). Institutionalised socialisation tactics have also been positively associated with the perceived fit (Kim, Cable, \& Kim, 2005). Nishanthi \& Kailasapathy (2018) conducted a study among employees in the banking sector in Sri Lanka and found that organisational socialisation positively influences the three components of organisational commitment.

Self-leadership strategies enable individuals to achieve specific, anticipated behavioural consequences (Neck \& Houghton, 2006). The selfleadership strategies may help newcomers to understand their task and role, co-workers and culture of the organisation. According to Cranmer, Goldman, and Houghton (2019), newcomers those practice behavioural focused strategies are actively engaging in seeking information and feedback that are related to the desired outcomes. While constructive thought strategies, for example, mental imagery and optimistic self-talk enable individuals to see the situation positively, natural reward strategies motivate newcomers to engage in social events of the organisation. Therefore, newcomers who exercise self- leadership are more likely to learn the task and task role, and become acceptable of the organisation, and rid off uncertainty and stress created by the discrepancies between the expectations and the reality, and thus they successfully socialised.

Self-leadership can be measured and outlined as three distinct components (Bailey et al., 2018; Houghton \& Neck, 2002; Houghton et al. 2004). Houghton and Neck (2002) empirically confirmed the existence of the threefactor model of self-leadership strategies, with significant parameters loading. Therefore this study proposed the following three hypotheses.

H1: Behaviour-focused strategies positively influence socialization.

H2: Constructive thought strategies positively influence socialization.

H3: Natural reward strategies positively influence socialization.

\section{Materials and Methods}

In the current study, to achieve the objectives, the researcher developed hypotheses based on existing theories and empirical evidence. Such deductive approach motivates the researcher to adopt a quantitative approach (Edmondson \& McManus, 2007). In addition to this reason, the researcher took a quantitative approach a) to maintain confidentiality and anonymity, b) to confirm the reliability and accuracy of the results, and c) to 
generalise the results to the population. As the current study was conducted with cross-sectional and self-reported data, it may expose to common method variance (CMV). To minimalise and detect $\mathrm{CMV}$, the researcher has taken the needed actions in the survey design stage and the data analysis stage. Particularly in the analysis stage, the researcher performed Harman's onefactor analysis and found that there is no one common factor that accounted for the majority of the covariance among the measures. Therefore it can be concluded that CMV is not a severe matter in the current research.

\section{Participants and Data Collection}

Two hundred newcomers who have less than one-year work experience in the current organisation were invited to the current study. Participants were invited from different banks in Sri Lanka. The researcher distributed 200 questionnaires to newcomers who have less than one year of work experience in the current organisation by visiting the potential respondents directly or through his network. To maintain confidentiality, the researcher avoided the questions that help to identify specific respondents. Participants were given questionnaires with a stamped cover and a cover letter promising confidentiality. Researcher advised the participants to send the filledquestionnaires directly to the researcher without noting their identity. Out of 200 questionnaires issued the researcher received only 124 $(62 \%)$ responses. Five responses were removed because of er very high number of missing values. Ultimately this study was conducted with 119 $(60 \%)$ responses.

Majority of the respondents were male ( $\mathrm{N}=68,57.1 \%$ ) and within the age group between 20 to30 ( $\mathrm{N}=69,58 \%)$. While eighty-one $(68.1 \%)$ respondents had a permanent appointment, the rest of the respondents had contract appointments. Table 1 shows the description of the respondent's profile data: gender, marital status, age, and employment type were presented in table 1.

\section{Table 1: Sample Composition}

\begin{tabular}{llcc}
\hline & & Count & Percentage \\
\hline \multirow{2}{*}{ Gender } & Male & 68 & $57.1 \%$ \\
& Female & 51 & $42.9 \%$ \\
\multirow{2}{*}{ Marital status } & Single & 89 & $74.8 \%$ \\
\multirow{2}{*}{ Age } & Married & 30 & $25.2 \%$ \\
\multirow{2}{*}{ Employment type } & Between 20 and 30 & 69 & $58.0 \%$ \\
& 30 and above & 50 & $42.0 \%$ \\
& Permanent & 81 & $68.1 \%$ \\
& Contract & 38 & $31.9 \%$ \\
\hline
\end{tabular}

Source: Analyzed data, 2020 


\section{Measurement Scales}

\section{Self-Leadership}

The researcher used the Revised SelfLeadership Questionnaire (RSLQ) to assess newcomer's self-leadership (Houghton and Neck, 2002). The RSLQ consists of 35 items that consider newcomer's enactment of three self-leadership strategies. Sample items include "I make a point to keep track of how well I'm doing at work", "I seek out activities in my work that I enjoy doing", and "Sometimes I picture in my mind a successful performance before I actually do a task". Respondents responded items on a 5-point Likert-type scale ( $1=$ strongly disagree and 5= strongly agree). The average score of all items in the scale was computed. Higher scores indicate greater levels of newcomer's enactment of self-leadership strategies. Previous studies (Andressen et al., 2012; Cranmer et al., 2019; Houghton and Neck, 2002) and the current research have shown satisfactory reliability score: Cronbach's $\alpha$ have ranged from 0.67 to 0.89 .

\section{Newcomer Socialisation}

Newcomer socialisation was assessed with a 35-item scale (Haueter et al., 2003). These items measure to what extent newcomers understand the task, workgroup, organisation and become an acceptable member of the organisation. Example items include "I understand how to perform the tasks that make up my job", "I understand how to behave in a manner consistent with my work group's values and ideals", "I understand this organisation's objectives and goals." The average score of all items in the scale was computed. Higher scores indicate greater levels newcomer's socialisation. High-level reliability coefficients of the scale in the previous studies (Cranmer et al., 2019; Haueter et al., 2003) and the current study have been observed: Cronbach's $\alpha$ have ranged from 0.88 to 0.92 . Respondents are advised to answer each question on 5 -point Likert-type scales ( $1=$ strongly disagree and $5=$ strongly agree).

\section{Data Analysis Techniques}

The data cleaning process was carried out through SPSS 22. Following the data cleaning, the researcher performed factor analysis to see if the scale consists of the three-factor model of the self-leadership construct as expected. The results showed the three-factor model (behavioural focused, natural rewards and constructive thoughts) with significant items loading. Each factor showed satisfactory Cronbach's $\alpha$ value $(>0.7)$. Then, the proposed hypotheses have been tested via regression analysis. Also, this study, assess the influence of respondent's profile data on their socialisation by controlling them when the main effect of the variable was evaluated.

\section{Data Analysis and Results}

During the data cleaning process, missing values, data distribution and outliers were checked, a few deviations were observed, and they were appropriately treated. Missing points were replaced with mean value except the five responses removed from the received response because of a high number of missing points. Table 2 provides mean standard deviation (STD), and correlations among these measures. 
Table 2: Correlation Statistics

\begin{tabular}{lccclllllll}
\hline Variables & Mean & STD & CrA & 1 & 2 & 3 & 4 & 5 & 6 & 7 \\
\hline Gender (1) & 1.42 & .49 & - & 1 & & & & & & \\
Marital_St (2) & 1.25 & .43 & - & .16 & 1 & & & & \\
Age (3) & 1.42 & .49 & - & $-.22^{*}$ & $.32^{* *}$ & 1 & & & \\
Employment type (4) & 1.31 & .46 & - & .17 & -.10 & .14 & 1 & & & \\
BE_S (5) & 2.28 & 1.40 & .69 & .12 & .00 & .02 & .11 & 1 & & \\
NT_S(6) & 3.26 & 1.23 & .71 & .07 & -.05 & -.09 & .04 & $.20^{*}$ & 1 & \\
CT_S (7) & 3.21 & 1.11 & .72 & -.03 & -.04 & .06 & .13 & $.32^{* *}$ & $.31^{* *}$ & 1 \\
Social (8) & 3.10 & 1.07 & .78 & .08 & .09 & -.11 & -.04 & $.46^{* *}$ & $.34^{* *}$ & $.43^{* * *}$ \\
\hline
\end{tabular}

*. Correlation is significant at the 0.05 level.

**. Correlation is significant at the 0.01 level.

Source: Analyzed data, 2020

\section{Hypotheses Testing}

The researcher employed hierarchical multiple regression to test the proposed three hypotheses, and the influence of the respondent's profile on the dependent variable: organisational socialisation. The first, researcher entered the control (respondents' profile data ) variables. In the next step, the researcher introduced the three predictor variables of socialisation (behaviour-focused strategies, natural rewards strategies and constructive thought strategies). The outcomes of multiple regression analysis are shown in table 3.
The results showed that control variables- gender, marital status, age, and type of appointment have not any significant influence on newcomer's socialisation. Further, the results showed that the three-component of self-leadership had a positive impact on newcomer's socialisation. behavioural focused strategies $(\beta=$ 0.265 ), natural rewards strategies $(\beta=$ $0.159)$ and constructive thought strategies $(\beta=0.286)$ all have positive and significant influence on newcomers socialization.

Table 3: Multiple Regression Analysis

\begin{tabular}{|c|c|c|c|c|c|c|c|c|}
\hline \multicolumn{2}{|c|}{ Model } & \multirow{2}{*}{$\begin{array}{c}\text { B } \\
3.130\end{array}$} & \multirow{2}{*}{$\begin{array}{l}\text { Sig. } \\
.000\end{array}$} & \multirow[t]{2}{*}{ VIF } & \multirow[t]{2}{*}{$\mathbf{R}^{2}$} & \multirow[t]{2}{*}{$\begin{array}{c}\mathbf{R}^{2} \\
\text { Change }\end{array}$} & \multirow[t]{2}{*}{$\begin{array}{c}\text { F } \\
\text { Change }\end{array}$} & \multirow[t]{2}{*}{$\begin{array}{c}\text { Sig. F } \\
\text { Change }\end{array}$} \\
\hline Model & (Constant) & & & & & & & \\
\hline \multirow[t]{4}{*}{1} & Gender & .063 & .773 & 1.2 & \multirow{4}{*}{.033} & \multirow{4}{*}{.033} & \multirow{4}{*}{.987} & \multirow{4}{*}{.418} \\
\hline & Marital status & .330 & .199 & 1.2 & & & & \\
\hline & Age & -.334 & .150 & 1.3 & & & & \\
\hline & $\begin{array}{l}\text { Employment } \\
\text { type }\end{array}$ & -.039 & .864 & 1.1 & & & & \\
\hline Model & (Constant) & 1.405 & .005 & & \multirow{8}{*}{.393} & \multirow{8}{*}{.359} & \multirow{8}{*}{21.868} & \multirow{8}{*}{.000} \\
\hline \multirow[t]{7}{*}{2} & Gender & -.023 & .899 & 1.2 & & & & \\
\hline & M_ST & .395 & .057 & 1.2 & & & & \\
\hline & Exper & -.366 & .051 & 1.3 & & & & \\
\hline & Emp_Type & -.214 & .243 & 1.1 & & & & \\
\hline & BF_S & $.265^{* * *}$ & .000 & 1.1 & & & & \\
\hline & NR_S & $.159 *$ & .023 & 1.1 & & & & \\
\hline & CT_S & $.286 * *$ & .000 & 1.2 & & & & \\
\hline
\end{tabular}


The contribution of control variables in explaining the variance in socialisation $\left(\mathrm{R}^{2}=0.33,3.3 \%\right)$ is not significant. The three components of self-leadership together explain $35.9 \%\left(\mathrm{R}^{2}=.359 \%\right)$ of the variance in newcomers' socialisation. The results showed that newcomers who enact behaviourfocused strategies, natural rewards strategies, and cognitive thought strategies are experienced successful socialisation. Therefore the three hypotheses that a) behavioural focused strategies positively influence socialisation, b) constructive thought strategies positively influence socialisation, and c) natural reward strategies positively influence socialisation have been accepted.

\section{Discussion and Conclusion}

The present study aimed to investigate the influence of self-leadership on newcomer's socialisation. The results indicated that the three-component of self-leadership: behavioural focused, natural rewards, and cognitive thought strategies had a positive and significant influence on newcomers socialisation. Also, this study explored that respondents profile variables have no significant influence on newcomers' socialisation. This study showed that newcomers who enact self-leadership strategies are more likely to socialise their transition from outside member to inside member successfully. Selfleadership facilitates newcomer's socialisation by providing the incentives and clear goals required to find organisational resources (Cranmer et al., 2019) that reduce uncertainty and stress created during the transition (Gruma \& Sake 2013).
Individuals' self- initiated activities in the socialisation process has become more vital because it reduces the burden of the organisation and leads to successful socialisation (Ashford \& Black, 1996; Cranmer et al., 2019; Kowsikka and James, 2019). Though a few studies investigated the influence of newcomer's proactive behaviour on the adjustment and socialisation process the direct impact of selfleadership has not been investigated except one study (Cranmer et al., 2019) that examine the influence of newcomer's commitment through selfleadership and socialisation. In the Sri Lankan context, Kowsikka and James (2019) examined the influence of newcomer's proactive behavior on socialisation and found proactive behaviours are the significant predictors of newcomers adjustment/socialisation. Nevertheless, the current study is the first study that investigates the direct impact of the three self-leadership strategies on socialisation in the Sri Lankan context.

\section{Implications}

The current study is the first study that investigates the influence of selfleadership on organisational socialisation among Sri Lankan participants. The results of the present study suggest that self-leadership enables employees to socialise into the organisation's context by allowing conditions in which newcomers can successfully adjust to their task, workgroup and the organisational culture. This study contributes to organisational socialisation literature by forwarding newcomers' selfleadership as a significant predictor of organisational socialisation. 
The findings of the current study suggest that an organisation should take necessary steps to enhance newcomer's self-leadership competencies. Self-leadership abilities can be developed (Neck \& Houghton, 2006). By enhancing newcomers' selfleadership organisation can build empowered employees and reduce the responsibility of the organisation in the newcomer socialisation process. An organisation can build a workforce with self-leadership through appropriate selection and training process (Cranmer, et al., 2019. Oliphant et al., 2008). Self-leadership capabilities are positively associated to many individual-level consequences such as individual performance, job satisfaction, positive affect, innovative behaviour, self-efficacy (Frayne \& Geringer 2000; Neck \& Manz 1996, Houghton et al., 2012). Therefore, individuals are advised to take necessary steps to develop their selfleadership capabilities. Individuals can develop self-leadership abilities through participating self-leadership training program and practicing selfmanagement control in their day-today life.

\section{Limitation and Directions for Future Studies}

While the current research provides an initial empirical examination about the impact of self-leadership on organisational socialisation, it is subject to some limitations. The researcher, in the current study, ignored the diverse internal environmental factors of different banks that can influence new comer's socialisation level. This study was conducted with cross-sectional and self-reported data that might contribute to the common method bias (CMB). Some scholars highlight that the risk of $\mathrm{CMB}$ has been exaggerated (Spector, 2006); however, the researcher has taken initial steps to minimise the CMV. Nevertheless, these steps are not sufficient to eliminate CMB (Podsakoff et al., 2003). As this study is a cross-sectional, it limits the cause and effect interpretation. Therefore, reported results should be elucidated with caution. This study limits the generalizability of the findings as it was conducted with one one country sample. Conducting further research by adopting a longitudinal approach and using a sample from different countries can enrich the interpretation and generalizability of the findings. Though this study found the direct influence of self-leadership on socialisation, it is essential to understand how self-leadership can influence on socialisation. Further, surveys can be directed to find the mediating (e.g. perceived politics) and moderating variable (e.g. organisational support) on the relationship between self-leadership and socialisation.

\section{References}

Andressen, P., Konradt, U., \& Neck, C. P. (2012). The relation between selfleadership and transformational leadership: Competing models and the moderating role of virtuality. Journal of Leadership \& Organizational Studies, 19(1), 68-82. 
Ashford, S. J., \& Black, J. S. (1996). Proactivity during organizational entry: The role of desire for control. Journal of Applied Psychology, 81(2), 199-214.

Ashforth, B. E., Sluss, D. M., \& Saks, A. M. (2007). Socialization tactics, proactive behavior, and newcomer learning: Integrating socialization models. Journal of Vocational Behavior, 70(3), 447-462.

Bailey, S. F., Barber, L. K., \& Justice, L. M. (2018). Is self-leadership just selfregulation? Exploring construct validity with HEXACO and self-regulatory traits. Current Psychology, 37(1), 149-161.

Bandura, A. (1988). Self-efficacy conception of anxiety. Anxiety Research, 1(2), 7798.

Bandura, A. (2001). Social cognitive theory of mass communication. Media Psychology, 3(3), 265-299.

Bauer, T. N., Bodner, T., Erdogan, B., Truxillo, D. M., \& Tucker, J. S. (2007).

Newcomer adjustment during organizational socialization: A meta-analytic review of antecedents, outcomes, and methods. Journal of Applied Psychology, 92(3), 707.

Berger, C. R., \& Calabrese, R. J. (1975). Some explorations in initial interaction and beyond: Toward a developmental theory of interpersonal communication. Human Communication Research, 1(2), 99-112.

Black, J. S., \& Ashford, S. J. (1995). Fitting in or making jobs fit: Factors affecting mode of adjustment for new hires. Human Relations, 48(4), 421-437.

Cable, D. M., \& Parsons, C. K. (2001). Socialization tactics and person-organization fit. Personnel Psychology, 54(1), 1-23.

Carver, C. S., \& Scheier, M. F. (1982). Control theory: A useful conceptual framework for personality-social, clinical, and health psychology. Psychological Bulletin, 92(1), 111-135

Cooper-Thomas, H. D. and Anderson, N. (2006). Organisational socialisation: a new theoretical model and recommendations for future research and HRM practices in organisations, Journal of Managerial Psychology. 21 (5), 492516.

Cooper-Thomas, H. D., \& Burke, S.E. (2012). Newcomer proactive behavior: can there be too much of a good thing", in Wanberg, C.R. (Ed.), The Oxford Handbook of Organizational Socialization, Oxford University Press, 56-77.

Cranmer, G. A., Goldman, Z. W., \& Houghton, J. D. (2019). I'll do it myself: selfleadership, proactivity, and socialisation. Leadership \& Organization Development Journal. DOI 10.1108/LODJ-11-2018-0389 
Edmondson, A. C., \& McManus, S. E. (2007). Methodological fit in management field research. Academy of Management Review, 32(4), 1246-1264.

Ellis, A. M., Nifadkar, S. S., Bauer, T. N., \& Erdogan, B. (2017). Newcomer adjustment: Examining the role of managers' perception of newcomer proactive behavior during organizational socialization. Journal of Applied Psychology, 102(6), 993-1001.

Frayne, C. A., \& Latham, G. P. (1987). Application of social learning theory to employee self-management of attendance. Journal of Applied Psychology, 72(3), 387.

Haueter, J. A., Macan, T. H., \& Winter, J. (2003). Measurement of newcomer socialization: Construct validation of a multidimensional scale. Journal of Vocational Behavior, 63(1), 20-39.

Hobfoll, S. E., Johnson, R. J., Ennis, N., \& Jackson, A. P. (2003). Resource loss, resource gain, and emotional outcomes among inner city women. Journal of Personality and Social Psychology, 84(3), 632-643

Houghton, J. D., \& Neck, C. P. (2002). The revised self-leadership questionnaire. Journal of Managerial Psychology, 17(8), 672-691.

Houghton, J. D., Wu, J., Godwin, J. L., Neck, C. P., \& Manz, C. C. (2012). Effective stress management: A model of emotional intelligence, self-leadership, and student stress coping. Journal of Management Education, 36(2), 220-238.

James, R. (2020). The Role of Newcomers' Proactive Behaviors on Well-Being, Engagement and Turnover. International Journal of Business Excellence. DOI: 10.1504/IJBEX.2020.10030908

James, R. \& Azungah, T. (2019). Repatriation of academics: organisational support, adjustment and intention to leave", Management Research Review. doi.org/10.1108/MRR-04-2019-0151

James, R. \& Azungah, T. (2020). Repatriation of academics: re-socialisation and adjustment. International Journal of Business Excellence. DOI: 10.1504/IJBEX.2020.10030908

Jones, G. R. (1986). Socialization tactics, self-efficacy, and newcomers' adjustments to organizations. Academy of Management Journal, 29(2), 262-279.

Kim, T., Cable, D. M., \& Kim, S. (2005). Socialisation tactics, employee proactivity, and person-organisation fit. Journal of Applied Psychology, 90(2), 232-241.

Kowsikka, F. M. J. J., \& James, R. (2019). Newcomers' socialisation: the proactive behaviors, satisfaction and social integration. Journal of Business Studies, 6(1), 89-107. 
Kowtha, N. R. (2011). School-to-work transition and newcomer socialisation: The role of job-related education. Journal of Management and Organization, 17(6), 747-763.

Kramer, M. W., \& Miller, V. D. (2014). Socialization and assimilation: Theories, processes, and outcomes. The SAGE Handbook of Organizational Communication: Advances in Theory, Research, and Methods, 525-547.

Kramer, M. W. and Miller, V. D. (2014), "Socialization and assimilation: theories, processes, and outcomes", in Putnam, L.L. and Mumby, D.K. (Eds), The Sage Handbook of Organizational Communication: Advances in Theory, Research, and Methods, Sage, Thousand Oaks, CA, 525-547.

Latham, G. P., Frayne, C. A. (1989). Self-management training for increasing job attendance: a follow-up and a replication. J. Appl. Psychol. 74:411-16

Louis, M. R. (1980). Surprise and sense making: What newcomers experience in entering unfamiliar organisational settings. Administrative Science Quarterly, 25(2), 226-251.

Manz, C. C. (1986). Self-leadership: Toward an expanded theory of self-influence processes in organizations. Academy of Management Review, 11(3), 585-600.

Manz, C. C. (1992). Self-leading work teams: Moving beyond self-management myths. Human Relations, 45(11), 1119-1140.

Murphy, S. E., \& Ensher, E. A. (2001). The role of mentoring support and selfmanagement strategies on reported career outcomes. Journal of Career Development, 27(4), 229-246.

Neck, C. P., \& Houghton, J. D. (2006). Two decades of self-leadership theory and research. Journal of Managerial Psychology.

Neck, C. P., \& Manz, C. C. (1996). Thought self-leadership: The impact of mental strategies training on employee cognition, behavior, and affect. Journal of Organizational Behavior, 17(5), 445-467.

Neck, C.P., Manz, C.C., \& Houghton, J.D. (2017), Self-Leadership: The Definitive Guide to Personal Excellence, Sage, Thousand Oaks, CA.

Nishanthi, H. M., \& Kailasapathy, P. (2018). Employee commitment: the role of organizational socialization and protean career orientation. South Asian Journal of Human Resources Management, 5(1), 1-27.

Podsakoff, P. M., MacKenzie, S. B., Lee, J. Y., \& Podsakoff, N. P. (2003). Common method biases in behavioral research: a critical review of the literature and recommended remedies. Journal of Applied Psychology, 88(5), 879. 
Politis, J. D. (2006). Self-leadership behavioural-focused strategies and team performance. Leadership \& Organization Development Journal, 27(3), 203216

Prussia, G. E., Anderson, J. S., \& Manz, C. C. (1998). Self-leadership and performance outcomes: the mediating influence of selfefficacy. International Journal of Industrial, Occupational and Organizational Psychology and Behavior, 19(5), 523-538.

Raabe, B., Frese, M., \& Beehr, T. A. (2007). Action regulation theory and career selfmanagement. Journal of Vocational Behavior, 70(2), 297-311.

Riordan, C. M., Weatherly, E. W., Vandenberg, R. J., \& Self, R. M. (2001). The effects of pre-entry experiences and socialisation tactics on newcomer attitudes and turnover. Journal of Managerial Issues, 13(2), 159-176.

Riordan, C. M., Weatherly, E. W., Vandenberg, R. J., \& Self, R. M. (2001). The effects of pre-entry experiences and socialization tactics on newcomer attitudes and turnover. Journal of Managerial Issues, 159-176.

Saks, A. M., \& Ashforth, B. E. (1997). Organizational socialization: Making sense of the past and present as a prologue for the future. Journal of Vocational Behavior, 51(2), 234-279.

Saks, A. M., \& Gruman, J. A. (2012). Getting newcomers on board: A review of socialization practices and introduction to socialization resources theory. The Oxford Handbook of Organizational Socialization, 27-55.

Saks, A. M., Gruman, J. A., \& Cooper-Thomas, H. (2011). The neglected role of proactive behavior and outcomes in newcomer socialization. Journal of Vocational Behavior, 79(1), 36-46.

Saks, A. M., \& Ashforth, B. E. (1996). Proactive socialisation and behavioral selfmanagement. Journal of Vocational Behavior, 48(3), 301-323.

Stewart, G. L., Courtright, S. H., \& Manz, C. C. (2011). Self-leadership: A multilevel review. Journal of Management, 37(1), 185-222.

Stewart, G. L., Courtright, S. H., \& Manz, C. C. (2019). Self-leadership: A paradoxical core of organizational behavior. Annual Review of Organizational Psychology and Organizational Behavior, 6, 47-67.

Taormina, R. J. (2008). Interrelating leadership behaviors, organizational socialization, and organizational culture. Leadership \& Organization Development Journal, 29(1), 85-102

Uhl-Bien, M., \& Graen, G. B. (1998). Individual self-management: Analysis of professionals' self-managing activities in functional and cross-functional work teams. Academy of Management Journal, 41(3), 340-350. 
Robinson James, KJHRM 2020, 15(01)

Van Maanen, J. and Schein, E.H. (1979. Toward a theory of organisational socialisation, in Staw, B.M. (Ed.), Research in Organizational Behavior, JAI Press, Greenwich, CT, pp. 209-264. 